\title{
Thoracoscopic lobectomy for clinical N2 and N1 lung cancer: Innovation outpacing standard of care
}

\author{
Bryan M. Burt, MD
}

\author{
From the Division of General Thoracic Surgery, Department of Surgery, Baylor College of Medicine, Houston, \\ Tex \\ Disclosures: Author has nothing to disclose with regard to commercial support. \\ Received for publication Dec 20, 2016; accepted for publication Dec 27, 2016; available ahead of print Feb 4, \\ 2017. \\ Address for reprints: Bryan M. Burt, MD, Division of General Thoracic Surgery, Department of Surgery, Baylor \\ College of Medicine, One Baylor Plaza, BCM 390, Houston, TX 77005 (E-mail: bryan.burt@bcm.edu). \\ J Thorac Cardiovasc Surg 2017;153:977-8 \\ $0022-5223 / \$ 36.00$ \\ Copyright (C) 2017 by The American Association for Thoracic Surgery \\ http://dx.doi.org/10.1016/j.jtcvs.2016.12.022
}

During the past 2 decades, our field has been empowered by a truly remarkable expansion of practice-changing minimally invasive surgical techniques, epitomized by the birth and adoption of thoracoscopic lobectomy. Since the first description of thoracoscopic lobectomy in 1994, ${ }^{1}$ innumerable studies have compared thoracoscopic lobectomy and lobectomy by thoracotomy for early-stage lung cancer. The balance of the literature has demonstrated improved short-term functional recovery, less incisional pain, and decreased morbidity with the thoracoscopic approach, and retrospective data support oncologic comparability to lobectomy by thoracotomy (nicely reviewed and debated by Klapper and colleagues ${ }^{2}$ and Chen and associates ${ }^{3}$ ).

Driven by the foresight and perseverance of surgeon innovators, we have witnessed a multidimensional evolution of minimally invasive techniques for pulmonary lobectomy, including robotic lobectomy, uniportal thoracoscopic lobectomy, "microlobectomy," and thoracoscopic lobectomy performed without endotracheal tube intubation. Paralleling and incorporated into the evolution of surgical technique has been an expansion of the indications for thoracoscopic lobectomy. The foundation of supportive evidence for minimally invasive lobectomy in non-small cell lung cancer (NSCLC) is built on patients with clinical stage I disease; however, recent years have highlighted our growing experience with locally advanced disease. For example, some series have demonstrated the feasibility of thoracoscopic bronchial sleeve and pulmonary artery sleeve lobectomy, ${ }^{4}$ hybrid thoracoscopic lobectomy with en bloc chest wall resection, ${ }^{5}$ and thoracoscopic pneumonectomy. ${ }^{6}$ Others have reported the safety and feasibility of advanced thoracoscopic resection of large tumors $(>5 \mathrm{~cm})$, resection of T3 or T4 tumors, resection of tumors after neoadjuvant therapy, and other extended anatomic resections. 7,8

In this issue of the Journal, Chen and colleagues ${ }^{9}$ retrospectively report the results of thoracoscopic lobectomy for advanced NSCLC from a multi-institutional database composed of 7 Chinese comprehensive cancer centers. A

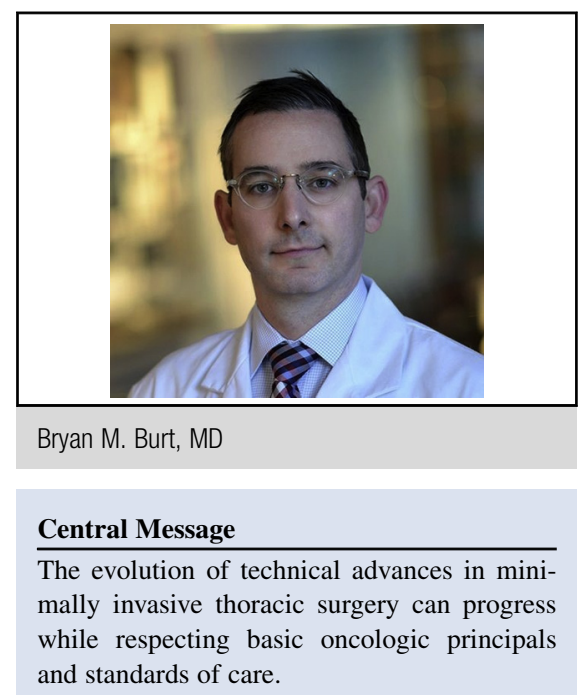

See Article page 967.

propensity-matched analysis of patients with clinical stage II to IIIA NSCLC was performed to compare thoracoscopic lobectomy ( $\mathrm{n}=120$ ) with lobectomy by thoracotomy ( $n=120)$. On the basis of similar rates of complications and similar metrics of disease-free and overall survival, Chen and colleagues ${ }^{9}$ concluded that thoracoscopic lobectomy can be performed for locally advanced stage NSCLC without compromising perioperative outcomes or oncologic efficacy.

A critical point for the reader to consider in this article is composition of the study cohort. To be eligible for this study, patients were required to have "clinical locally advanced" stage (II-IIIA), which was accounted for predominantly by clinically node positive disease, present in $72 \%$ of patients in the thoracoscopy group and $73 \%$ of patients in the open group. Only $13 \%$ of patients in the thoracoscopy group and only $17 \%$ of patients in the open group had advanced stage by $\mathrm{T}$ descriptor criteria (T3-T4). Somewhat surprising to the Western audience will be the $37 \%$ and $40 \%$ prevalences of clinical $\mathrm{N} 2$ disease in the thoracoscopy and open groups, respectively, when it is realized that neoadjuvant therapy was administered in only $3 \%$ to $4 \%$ of patients in the entire cohort. Whereas it is certain that international practice patterns vary, upfront lobectomy for clinical stage IIIA NSCLC by N2 disease falls outside the standard of care in North America, and this point must be emphasized to our readers. Such patients are best treated with either definitive concurrent chemoradiation or induction 
chemotherapy with or without radiotherapy, followed by surgery, ${ }^{10}$ and it is in fact a quality measure of the American College of Surgeons Commission on Cancer that surgery is not the first course of treatment for clinical N2 disease. ${ }^{1}$

That being said, Chen and colleagues ${ }^{9}$ are to be congratulated for a well-designed and well-executed study of thoracoscopic lobectomy for patients with clinical node-positive lung cancer, a factor than can increase the technical complexity of these resections. As a specialty, we have the insight to recognize this as a contribution of advancing technique that can be applied as appropriate to our practices while maintaining the best oncologic standards of care for our patients.

\section{References}

1. McKenna RJ Jr. Thoracoscopic lobectomy with mediastinal sampling in 80-yearold patients. Chest. 1994;106:1902-4.

2. Klapper J, D'Amico TA. VATS versus open surgery for lung cancer resection: moving toward a minimally invasive approach. J Natl Compr Cancer Netw. 2015;13:162-4.

3. Cheng AM, Wood DE. VATS versus open surgery for lung cancer resection: moving beyond the incision. J Natl Compr Canc Netw. 2015;13:166-70.
4. Huang J, Li J, Qiu Y, Xu X, Sekhniaidze D, Chen H, et al. Thoracoscopic double sleeve lobectomy in 13 patients: a series report from multi-centers. J Thorac Dis. 2015; 7:834-42.

5. Berry MF, Onaitis MW, Tong BC, Balderson SS, Harpole DH, D'Amico TA. Feasibility of hybrid thoracoscopic lobectomy and en-bloc chest wall resection. Eur J Cardiothorac Surg. 2012;41:888-92.

6. Battoo A, Jahan A, Yang Z, Nwogu CE, Yendamuri SS, Dexter EU, et al. Thoracoscopic pneumonectomy: an 11-year experience. Chest. 2014;146: 1300-9.

7. Gonzalez-Rivas D, Fieira E, Delgado M, Mendez L, Fernandez R, de la Torre M. Is uniportal thoracoscopic surgery a feasible approach for advanced stages of non-small cell lung cancer? J Thorac Dis. 2014;6:641-8.

8. Nakanishi R, Fujino Y, Yamashita T, Shinohara S, Oyama T. Thoracoscopic anatomic pulmonary resection for locally advanced non-small cell lung cancer. Ann Thorac Surg. 2014:97:980-5.

9. Chen K, Wang X, Yang F, Li J, Jiang G, Liu J, et al. Propensity-matched comparison of video-assisted thoracoscopic with thoracotomy lobectomy for locally advanced non-small cell lung cancer. J Thorac Cardiovasc Surg. 2017;153: 967-76.

10. Ettinger DS, Wood DE, Akerley W, Bazhenova LA, Borghaei H, Camidge DR, et al. National Comprehensive Cancer Network. Non-small cell lung cancer, version 6.2015. J Natl Compr Cancer Netw. 2015;13:515-24.

11. National Cancer Database. Cancer Programs Practice Profile Report $\left(\mathrm{CP}^{3} \mathrm{R}\right)$, version 3. Lung measure specifications. Available at: https://www.facs.org/ /media/files/ quality programs/cancer/ncdb/cp3roverview.ashx. Accessed December 15, 2016. 